\title{
Phytochemical investigation of crude methanol extracts of different species of Swertia from Nepal
}

\author{
Supreet Khanal ${ }^{1}$, Niroj Shakya ${ }^{1}$, Krishna Thapa ${ }^{1}$ and Deepak Raj Pant ${ }^{1,2^{*}}$
}

\begin{abstract}
Background: The genus Swertia is reported to contain potent bitter compounds like iridoids, xanthones and c-glucoflavones that are known to heal many human disorders. In contrast to high ethnomedicinally valued Swertia chirayita, its other species have not been studied extensively, in spite of their common use in traditional medicinal system in Nepalese communities. So, the present study attempts to investigate the content of total polyphenols, flavonoids, antioxidant activity and estimate the rough content of amarogentin, swertiamarin and mangiferin from different species of Swertia from Nepalese Himalayas.
\end{abstract}

Methods: Whole plant parts of S. chirayita (SCH), S. angustifolia (SAN), S. paniculata (SPA), S. racemosa (SRA), S. nervosa (SNE), S. ciliata (SCI) and S. dilatata (SDI) were collected; total phenolic and flavonoid contents were quantified spectrophotometrically and in vitro DPPH free radical scavenging assay was measured. Thin layer chromatography was performed on TLC aluminium plates pre-coated with silica gel for identification of swertiamarin, amarogentin and mangiferin from those species and semi quantitative estimation was done using GelQuant.NET software using their standard compounds.

Results: The phenolic content was highest in the methanol extract of SCH ( $67.49 \pm 0.5 \mathrm{mg} \mathrm{GAE} / \mathrm{g}$ ) followed by SDI, SRA, SNE, SCI, SPA and SAN. The contents of flavonoids were found in the order of SCH, SPA, SRA, SNE, SDI, SCI and SAN. Promising concentration of phenolics and flavonoids produced promising DPPH free radical scavenging values. The IC50 values for the 2,2-diphenyl-1-picrylhydrazyl (DPPH) radical scavenging test was lowest in SCH $(23.35 \pm 0.6 \mu \mathrm{g} / \mathrm{ml})$, even lower than the standard ascorbic acid among the seven studied species. A significant correlation of 0.977 was observed between the polyphenol content and antioxidant values. The TLC profile showed the presence of all three major phytochemicals; amarogentin, swertiamarin and mangiferin in all of the plant samples.

Conclusion: Among the seven studied species, SCH showed anticipating results in total phenol content, flavonoid content and DPPH radical scavenging test. The less considered species of Swertia can be a potential source of bioactive amarogentin, and other useful therapeutic compounds in the alarming status of Swertia chirayita as shown by the phytochemical analysis.

Keywords: Swertia species, Antioxidant, TLC, Amarogentin, Swertiamarin, Mangiferin

\section{Background}

Plant kingdom is a source of medicines that show various potent bioactivities against different types of illness. Potential compounds are extracted and used in

\footnotetext{
*Correspondence: drpant_agbot@yahoo.com

${ }^{1}$ Central Department of Biotechnology, Tribhuvan University, Kirtipur,

Kathmandu, Nepal

Full list of author information is available at the end of the article
}

therapeutic applications in pharmaceutical industries for drug formulations [1]. The World Health Organization lists $11 \%$ of 252 basic drugs produced from flowering plants and one-fourth of all prescribed pharmaceutical drugs are directly or indirectly derived from plant sources [2]. Himalayan plants have been said to have very high chemical diversity and thus offers a potential source for the discovery of new and useful natural products for 
use in therapeutic applications [3]. Nepal harbors more than 7000 higher plants, $5 \%$ of which are endemic [4]. It is estimated that various communities in Nepal use approximately 1000 species of wild plants in traditional medicinal practice. Such plants of medicinal value have been routinely used for their home remedies, traditional therapies and daily livelihood in the rural communities [5]. The species of Swertia comprises the genus of such a potent medicinal plant with higher therapeutic and pharmacological applications [6].

Swertia is a native Himalayan genus with high ethnopharmacological significance and prominent trade value; Swertia chirayita being the most important species. The other species of Swertia are reported to be substitutes and alternatives to $S$. chirayita [6, 7]. However, almost all of the Swertia species are known to have some role in traditional medicine. Nepal harbors 31 species including five varieties of Swertia with Swertia acualis as the endemic species [7]. Nepal occupies a prominent percentage of Swertia distribution and more than $50 \%$ of its trade [8]. Swertia ranks high in terms of medicinal importance and drug value among the local Nepalese folklore. This high ethno-medicinal value has made Swertia one of the largest exports on medicinal plants and NTFPs from Nepal. Among the total 31 species of Swertia, nine species are commonly traded: Swertia chirayita, Swertia angustifolia, Swertia tetragona, Swertia racemosa, Swertia ciliata, Swertia dilatata, Swertia multicaulis, Swertia alata, and Swertia nervosa [9]. Different species of Swertia are reported to contain potent bitter compounds that stimulate the digestive system and are known to heal many digestion disorders [10]. They have bitter compounds called glycosides, seco-irridoids and xanthones that are responsible for the therapeutic effects and pharmacological activities [11, 12]. They use it as primary medicines in fever and enteric diseases mostly as infusion, decoction, paste and juice [7].

As there are many species of Swertia that are commonly traded in the chirayito trade, we have selected these species in terms of their importance in their trade. Keeping in view of their unpublished nature and very less studies being done in these species of Swertia from Nepalese Himalayas, we have investigated and analyzed the phytochemicals of S. angustifolia, S. paniculata, S. racemosa, S. nervosa S. ciliata and S. dilatata from Nepal as compared to published importance of Swertia chirayita.

\section{Methods}

\section{Chemicals and reagents}

2,2-diphenyl-1-picrylhydrazyl (DPPH), sodium carbonate, ascorbic acid and folin-ciocalteu phenol reagent was purchased from Merck Ltd, India; gallic acid from Moly Chem, Mumbai, quercetin from Sigma-Aldrich and Aluminium TLC plates of 250 microns were purchased from
Whattmann, Germany. The marker compound, Amarogentin was obtained from Chromadex USA; Mangiferin and Swertiamarin were obtained from ZeLang Pharma, Nanjing, China. All the reagents and chemicals including the solvents used in this experiment were of analytical grade.

\section{Plant samples}

Whole plants were collected from different places of Nepal during their flowering periods of August-October, 2013. The major collection sites were Dolakha, Rasuwa, Kathmandu and Palpa districts. Identification of the plants material was done by a taxonomist from Central Herbarium and Plant Laboratory, Lalitpur. Herbariums were prepared and voucher specimens were submitted for deposition at National Herbarium, Godawari, Lalitpur for future references. The collected plant materials (whole plants) (Additional files 1, 2, 3, 4, 5 and 6) were cleaned, shade dried for 7-8 days, powdered and stored on sterile and dry tubes for solvent extraction. The seven species of Swertia used in this experiment are Swertia chirayita (SCH), Swertia angustifolia (SAN), Swertia paniculata (SPA), Swertia racemosa (SRA), Swertia ciliata (SCI), Swertia nervosa (SNE) and Swertia dilatata (SDI).

\section{Preparation of methanol extracts}

Different powdered samples were extracted with $100 \%$ methanol $(10 \% \mathrm{w} / \mathrm{v})$. After percolation for $24 \mathrm{~h}$, these samples were subjected to ultrasonication for $2 \mathrm{~h}$ and centrifuged (Additional file 7). The solvent was filtered through two layers of Whatman No. 1 filter paper and methanol was evaporated on Rotatory Evaporator under the vacuum till the semi-solid mass was obtained. The percentage yield of the crude methanol extract obtained for different species were SCH (10.48\%), SAN (9.16\%), SPA (9.42 \%), SRA (12.17\%), SNE (9.38\%), SCI (8.2 \%) and SDI (7.98 \%).

\section{Phytochemical screening}

The major secondary metabolites like phenols, resins, flavonoids, terpenes, phytosterols, tannins and glycosides were screened with their respective tests from the methanol crude extracts of different species using various tests $[13,14]$.

\section{Determination of total flavonoid content}

The total flavonoid content in the plant extract was estimated using the Aluminium chloride colorimetric method [15]. $0.25 \mathrm{ml}$ of extract $(10 \mathrm{mg} / \mathrm{ml})$ was separately mixed with the $0.75 \mathrm{ml}$ of ethanol, $0.05 \mathrm{ml}$ of the $10 \%$ aluminum chloride, $0.05 \mathrm{ml}$ of the $1 \mathrm{M}$ potassium acetate and $1.4 \mathrm{ml}$ of the distilled water. The reaction mixture was incubated 
for $30 \mathrm{~min}$ at room temperature. Then absorbance of the mixture was measured at $415 \mathrm{~nm}$ using the UV-spectrophotometer (Thermo Fisher Scientific, Genesystem-10-5). The calibration curve was obtained with the help of the quercetin as standard dissolved in methanol with concentration from 10 to $100 \mu \mathrm{g} / \mathrm{ml}$. The total flavonoid content was expressed in terms of the milligram of Quercetin equivalent per gram of the dry mass (mg QE/g).

\section{Determination of total polyphenol content}

The total polyphenol content was determined spectrophotometrically [15] with slight modifications. For this $0.1 \mathrm{ml}$ of each extract $(2.5 \mathrm{mg} / \mathrm{ml})$ was separately mixed with the $1 \mathrm{ml}$ of Folin-Ciocalteu phenol reagent (1:10 dilution with distilled water) and $0.8 \mathrm{ml}$ of aqueous $1 \mathrm{M} \mathrm{Na}_{2} \mathrm{CO}_{3}$ solution. The reaction mixture was allowed to stand for about $15 \mathrm{~min}$ and then absorbance was measured at $765 \mathrm{~nm}$ using the UV-spectrophotometer (Thermo Fisher Scientific, Genesystem-10-5). A calibration curve was obtained using gallic acid in methanol using the concentration ranging from 25 to $250 \mu \mathrm{g} / \mathrm{ml}$ as standard. Based on this standard graph, the concentration of the individual samples was calculated. Total polyphenol content was expressed in terms of the milligrams of the Gallic acid equivalent per gram of the dry mass (mg GAE/g).

\section{Determination of antioxidant activity via DPPH free radical scavenging assay}

Total antioxidant activity of crude methanol extracts of different Swertia species was assessed on the basis of the radical scavenging effect of the stable 1,1-diphenyl-2 picryhydrazyl (DPPH)-free radical activity $[16,17]$. Different concentrations of plant extract $(30-270 \mu \mathrm{g} / \mathrm{ml})$ and ascorbic acid (10-100 $\mu \mathrm{g} / \mathrm{ml})$ were prepared in methanol. $0.5 \mathrm{ml}$ of samples of plant extract as well as ascorbic acid of each concentration was taken separately in clean test tubes. To this sample $0.5 \mathrm{ml}$ of the $0.2 \mathrm{mM}$ DPPH solution was added, properly mixed and incubated in dark for $30 \mathrm{~min}$. The control was prepared as above, without the plant extract or ascorbic acid and methanol was taken as blank. The absorbance was taken on spectrophotometer (Thermo Fisher Scientific, Genesystem-10-5) at $517 \mathrm{~nm}$.

Now the radical scavenging activity was calculated using the following formula.

$$
\begin{aligned}
& \text { \% Radical scavenging activity } \\
& \quad=\left(\text { Control }_{\mathrm{abs}}-\text { Sample }_{\mathrm{abs}}\right) / \text { Control }_{\mathrm{abs}} \times 100 \%
\end{aligned}
$$

Then a standard graph was plotted taking the concentration of Ascorbic acid on the $\mathrm{x}$-axis and percentage scavenging activity on the $y$-axis. Based on this standard graph, IC50 value of each sample was calculated based on the formula:
$I C 50=\operatorname{EXP}(L N($ conc $>50 \%))-(p i>50 \%-50 \%) /$

$(p i>50 \%-p i<50 \%) \times L N($ conc $>50 \% /$ conc $<50 \%)$

Detection and estimation of major phytochemicals by thin layer chromatography

Aluminum TLC plates were used for the initial detection and estimation of three major phytochemicals from crude methanol extracts. $2 \mathrm{mg} / \mathrm{ml}$ stock of each standard compounds amarogentin, mangiferin and swertiamarin was prepared and $5 \mu \mathrm{l}$ of methanol extracts of each seven samples were carefully run in suitable solvent systems [18]. Elution was done using ethyl acetate:methanol:water $(77: 15: 8 \mathrm{v} / \mathrm{v} / \mathrm{v})$ for amarogentin and swertiamarin and ethyl acetate:methanol:formicacid:water $(67: 17: 8: 8 \mathrm{v} / \mathrm{v} / \mathrm{v})$ for mangiferin. All the TLC separations were performed at room temperature and detection was carried out by UV light at $354 \mathrm{~nm}$. The various samples showed different intensities of the respective compounds inferring the presence of these compounds in varying amounts in those samples. The visualized compounds from TLC were quantified by the GelQuant.NET software provided by Biochemlab Solutions Co. [19] using reference compounds.

First calibration curves were prepared from standard marker solutions and peak areas in terms of pixels were plotted against the corresponding concentration. All seven crude methanol extracts were visualized for their respective marker compounds from TLC plates and pixel ratio for each band was calculated using GelQuant.NET software.

\section{Statistical analysis}

All the experiments were performed in triplicates and the data are reported as mean $\pm \mathrm{SD}$. Linear regression analysis was used to calculate total phenol content, flavonoid content and DPPH radical scavenging values. Pearson's correlation coefficient was calculated for phenol content and antioxidant values using Microsoft excel 2010. Statistical significance was determined among various treatments with one way ANOVA test for total phenol content, flavonoid content and IC50 and Tukey's test. Differences at $P<0.05$ were considered to be significant.

\section{Results and discussion \\ Phytochemical screening}

Qualitative phytochemical tests of crude methanol extracts of seven species of Swertia were performed from whole plants. The results of various chemical tests for the detection and identification of chemical constituents are summarized in Table 1. Baral et al. [20] studied phytochemical screening of S. chirayita, S. angustifolia, S. ciliata and S. dilatata from Nepalese Himalayas with acetone and methanol solvents. 
Table 1 Qualitative phytochemical analysis of different methanol extracts on different species of Swertia

\begin{tabular}{|c|c|c|c|c|c|c|c|c|}
\hline Plant extracts & $\begin{array}{l}\text { Alkaloids } \\
\text { Mayer's test }\end{array}$ & $\begin{array}{l}\text { Resins } \\
\text { Acetone } \\
\text { water test }\end{array}$ & $\begin{array}{l}\text { Phenols } \\
\text { Ferric chloride } \\
\text { test }\end{array}$ & $\begin{array}{l}\text { Flavonoids } \\
\text { Alkaline } \\
\text { reagent test }\end{array}$ & $\begin{array}{l}\text { Glycosides } \\
\text { Modified } \\
\text { Brontrager's test }\end{array}$ & $\begin{array}{l}\text { Diterpenes } \\
\text { Copper } \\
\text { acetate test }\end{array}$ & $\begin{array}{l}\text { Tannins } \\
\text { Gelatin } \\
\text { test }\end{array}$ & $\begin{array}{l}\text { Phytosterol } \\
\text { Salkowski's } \\
\text { test }\end{array}$ \\
\hline SCH-MET & +++ & ++ & +++ & +++ & ++ & ++ & + & ++ \\
\hline $\mathrm{SCH}-\mathrm{AQ}$ & + & - & + & - & + & - & - & + \\
\hline SAG-MET & +++ & + & ++ & ++ & + & ++ & ++ & + \\
\hline SAG-AQ & + & - & ++ & - & ++ & + & + & + \\
\hline SPA-MET & ++ & ++ & ++ & +++ & ++ & ++ & - & ++ \\
\hline SPA-AQ & + & + & + & + & + & - & - & + \\
\hline SRA-MET & +++ & - & ++ & ++ & + & + & + & ++ \\
\hline SRA-AQ & ++ & - & - & - & - & - & - & + \\
\hline SNE-MWT & ++ & ++ & ++ & + & ++ & ++ & - & - \\
\hline SNE-AQ & - & - & + & - & - & + & - & + \\
\hline SCI-MET & +++ & ++ & + & ++ & - & - & ++ & - \\
\hline $\mathrm{SCl}-\mathrm{AQ}$ & + & - & - & - & - & - & + & - \\
\hline SDI-MET & +++ & + & +++ & ++ & +++ & ++ & + & ++ \\
\hline SDI-AQ & ++ & + & - & + & + & - & - & + \\
\hline
\end{tabular}

+++ Highly Positive; ++ Moderately Positive; + Positive; - Negative or Not Detectable; MET Methanol; SCH Swertia chirayita; SAG Swertia angustifolia; SPA Swertia paniculata; SRA Swertia racemosa; SNE Swertia nervosa; SCI Swertia ciliata; SDI Swertia dilatata

\section{Total flavonoid content}

Standard graph of quercetin (Fig. 1) was first plotted for the estimation of total flavonoid content. Several flavonoids have been identified as potential inhibitors of oxidative enzymes in inflammatory processes that inhibit the metabolic disorders, heart diseases and cancers. Different classes of flavonoids are present in plants and are reported to possess varied pharmacological activities [21].

The contents of total flavonoids were measured by aluminium chloride method and expressed in terms of quercetin equivalent as $26.16 \pm 0.24 \mathrm{mg} \mathrm{QE} / \mathrm{g}$ for $\mathrm{SCH}$, $18.41 \pm 0.19 \mathrm{QE} / \mathrm{g}$ for SAN, $25.18 \pm 0.85 \mathrm{QE} / \mathrm{g}$ for SPA, $24.88 \pm 1.26 \mathrm{QE} / \mathrm{g}$ for SRA, $24.57 \pm 0.19 \mathrm{QE} / \mathrm{g}$ for SNE, $22.95 \pm 0.48 \mathrm{QE} / \mathrm{g}$ for SCI and $24.04 \pm 1.26 \mathrm{QE} / \mathrm{g}$ for SDI (Additional file 8). Table 2 summarizes the quantification of flavonoids and statistical significance among the falvanoids of each species. Chen et al. [22] estimated the total flavonoid content to be $4.98 \pm 0.40 \mathrm{mg}$ rutin equivalents/g in ethanol extract in Swertia chirayita dry weight and Tripathi et al. [23] reported $10.6 \mu \mathrm{g}$ equivalents of quercetin in $50 \mu \mathrm{g}$ of aqueous extract of Swertia chirayita. The flavonoids present in many plants probably inhibit cyclooxygenase enzyme activity showing antimicrobial and anti-parasitic activity [24].

\section{Total polyphenol content}

A calibration curve of gallic acid (Fig. 2) was used for the estimation of total polyphenol content. Phenolic components are potential antioxidants that donate hydrogen to free radicals and scavenge radicals such as singlet oxygen, superoxide and hydroxyl radicals [25]. It has been recognized that the phenolic-linked anti-oxidant property in medicinal plants are good antioxidants since the

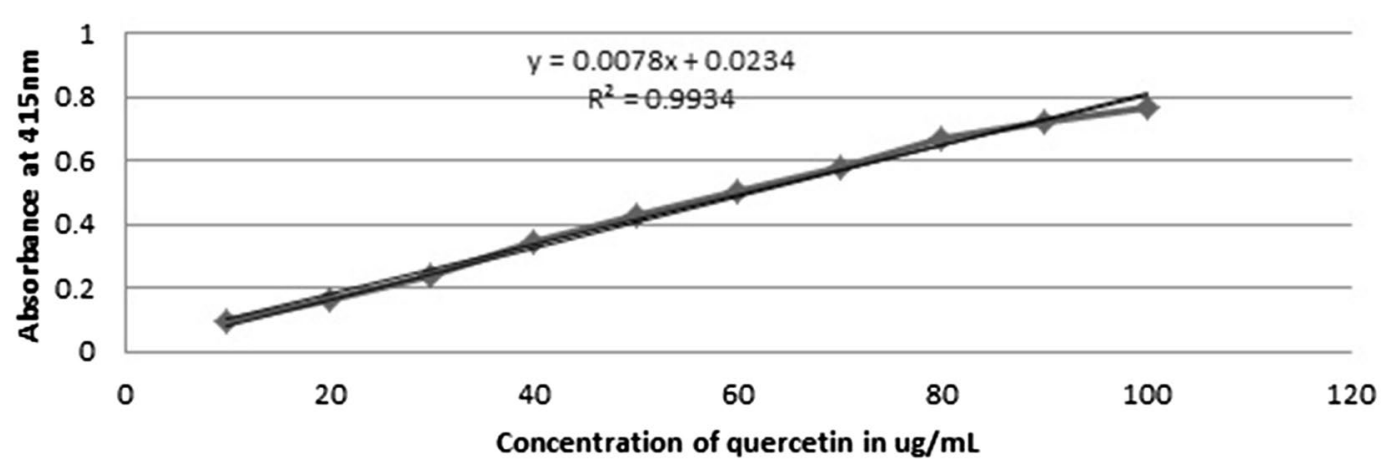

Fig. 1 Standard graph for quercetin 
Table 2 Total phenolic content, total flavonoid content and $I_{50}$ values of methanol extracts of different Swertia species

\begin{tabular}{llll}
\hline Swertia species & TFC $(\mathbf{m g}$ QE/g) & TPC (GAE/g) & IC $_{\mathbf{5 0}}(\boldsymbol{\mu g} / \mathbf{m l})$ \\
\hline S. chirayita & $26.16 \pm 0.25^{\mathrm{a}}$ & $67.49 \pm 0.50^{\mathrm{a}}$ & $23.35 \pm 0.59^{\mathrm{a}}$ \\
S. angustifolia & $18.41 \pm 0.19^{\mathrm{b}}$ & $22.68 \pm 0.78^{\mathrm{b}}$ & $45.81 \pm 1.54^{\mathrm{b}}$ \\
S. paniculata & $25.18 \pm 0.85^{\mathrm{a}}$ & $34.01 \pm 0.67^{\mathrm{c}}$ & $29.53 \pm 1.17^{\mathrm{c}}$ \\
S. racemosa & $24.88 \pm 1.26^{\mathrm{a}}$ & $66.91 \pm 1.02^{\mathrm{a}}$ & $30.34 \pm 1.14^{\mathrm{d}}$ \\
S. nervosa & $24.57 \pm 0.19^{\mathrm{a}}$ & $54.36 \pm 0.76^{\mathrm{d}}$ & $32.19 \pm 0.63^{\mathrm{c}}$ \\
S. ciliata & $22.95 \pm 0.48^{\mathrm{a}}$ & $42.53 \pm 0.91^{\mathrm{e}}$ & $29.99 \pm 0.96^{\mathrm{d}}$ \\
S. dilatata & $24.04 \pm 1.26^{\mathrm{a}}$ & $67.00 \pm 3.63^{\mathrm{a}}$ & $30.04 \pm 0.93^{\mathrm{d}}$ \\
\hline
\end{tabular}

In each column values with different letters are significantly different $(P<0.05)$ within different species

generation of reactive oxygen species has been linked to majority of the systemic diseases [26].

Total polyphenols in crude methanol extracts were estimated by Folin Ciocalteu reagent method and expressed in terms of Gallic acid equivalent as $67.49 \pm 0.5 \mathrm{mg} \mathrm{GAE} / \mathrm{g}$ for $\mathrm{SCH}, 22.68 \pm 0.78 \mathrm{GAE} / \mathrm{g}$ for SAN, $34.01 \pm 0.67 \mathrm{GAE} / \mathrm{g}$ for SPA, $66.91 \pm 1.02 \mathrm{GAE} / \mathrm{g}$ for SRA, $54.36 \pm 0.76 \mathrm{GAE} / \mathrm{g}$ for SNE, $42.53 \pm 0.91 \mathrm{GAE} / \mathrm{g}$ for SCI and $67.00 \pm 3.63$ GAE/g for SDI as reported in Table 2 (Additional file 9). The flavonoid content of $S$. chirayita has been previously reported in aqueous and $12 \%$ ethanolic extracts by Phoboo et al. [10]. Similarly, Chen et al. [22] and Dutta et al. [27], have reported the estimation of total phenolics in alcoholic solvents in the same plant.

\section{DPPH free radical scavenging assay}

Antioxidants are substances that delay oxidation process, inhibiting the polymerization chain initiated by free radicals and other subsequent oxidizing reactions [28]. DPPH is a stable free radical that accepts electron or hydrogen radical to become a stable diamagnetic radical which is scavenged by proton donating substrate. It has been reported that the decrease in the absorbance of DPPH radical caused by the phenol compounds is due to the reaction between antioxidant molecules and radicals resulting in the scavenging that discolors from purple to yellow [29]. The percentage radical scavenging activity of ascorbic acid and all of the methanol extracts showed a concentration dependent inhibition. Figure 3 shows the scavenging effects of various methanol extracts on DPPH free radicals in the order of $\mathrm{SCH}>\mathrm{SRA}>\mathrm{SDI}>\mathrm{SCI}>\mathrm{SP}$ $\mathrm{A}>\mathrm{SNE}>\mathrm{SAN}$. IC50 value for ascorbic acid was found to be $26.73 \pm 2.13 \mu \mathrm{g} / \mathrm{ml}$. IC50 values of Swertia extracts were calculated and compared with this standard value.

Among different crude methanol extracts, highest and lowest DPPH free radical scavenging was observed in $\mathrm{SCH}$ with $95.56 \%$ and SAN with $60.01 \%$ at $100 \mu \mathrm{g} /$ $\mathrm{ml}$ (Table 2). So, IC50 value was lowest for $\mathrm{SCH}$ as $23.35 \pm 0.6 \mu \mathrm{g} / \mathrm{ml}$ and highest for SAN as $45.81 \pm 1.54$ $\mu \mathrm{g} / \mathrm{ml}$. S. chirayita proves to be the best antioxidant among the studied species. As the other species also had better IC50 values, this proves the high pharmacological and therapeutic importance of this genus. Previous studies done on this plant have shown similar results. Phoboo et al. [10] has reported similar DPPH radical inhibition in ethanol root extracts of $S$. chirayita. Chen et al. [22] in ethanolic extract of Swertia chirayita exhibited a steady increase in inhibition percentage. Antioxidant activities of methanol extracts demonstrated by Hajimehdipoor [30] showed that S. longifolia aerial parts and roots had considerable radical scavenging activity.

\section{Correlation between total phenol content and DPPH free radical scavenging}

Most antioxidant activities from plant sources are correlated with phenolic-type compounds [22]. Phenols are considered important antioxidants in foods and medicinal plants. Swertia species extracts contain many naturally occurring poly hydroxyxanthones and flavonoids

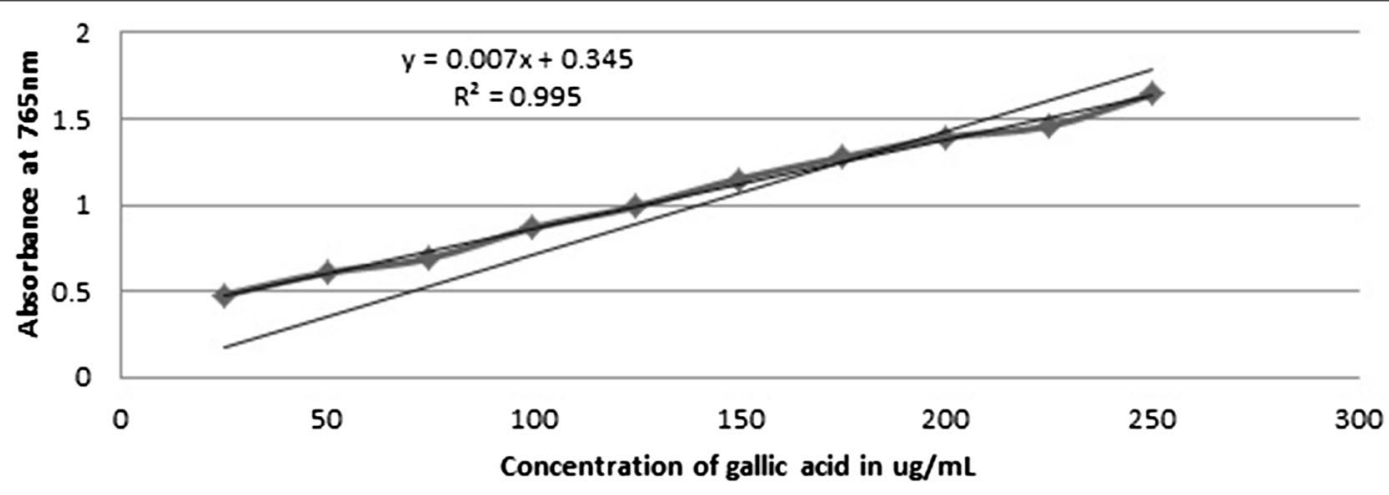

Fig. 2 Standard graph for gallic acid 


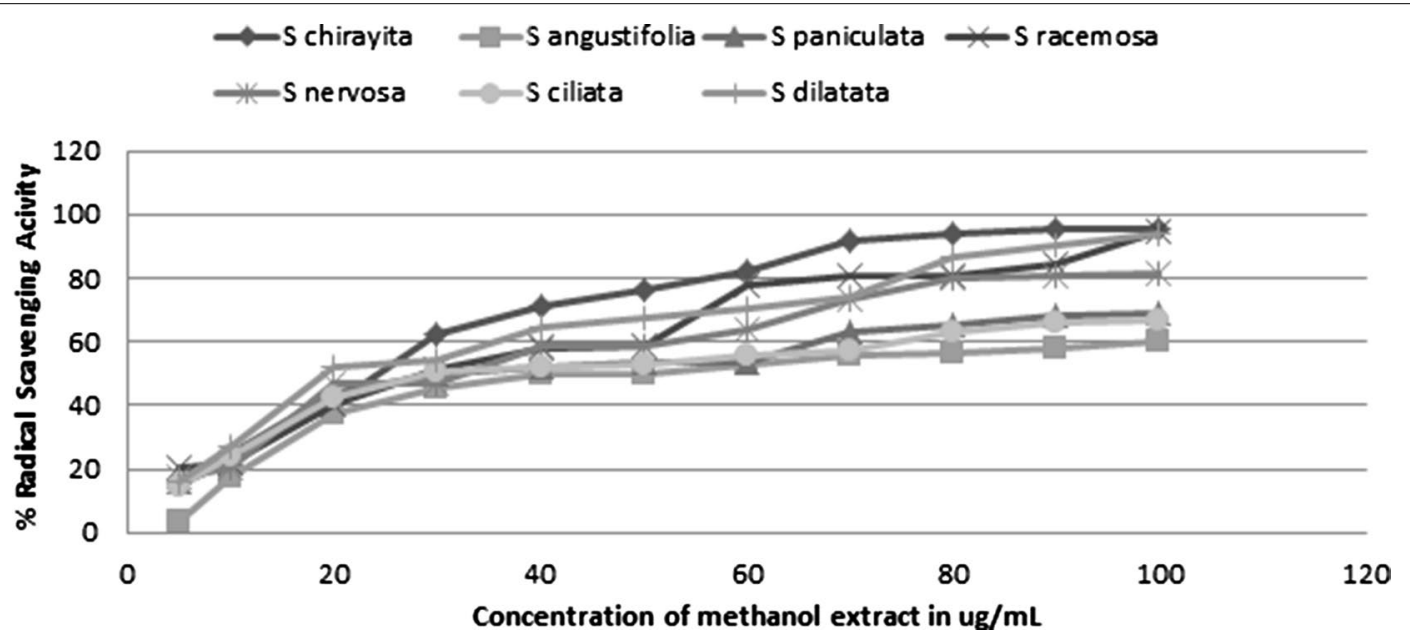

Fig. 3 Percentage DPPH radical scavenging activity of methanol extracts of different Swertia species

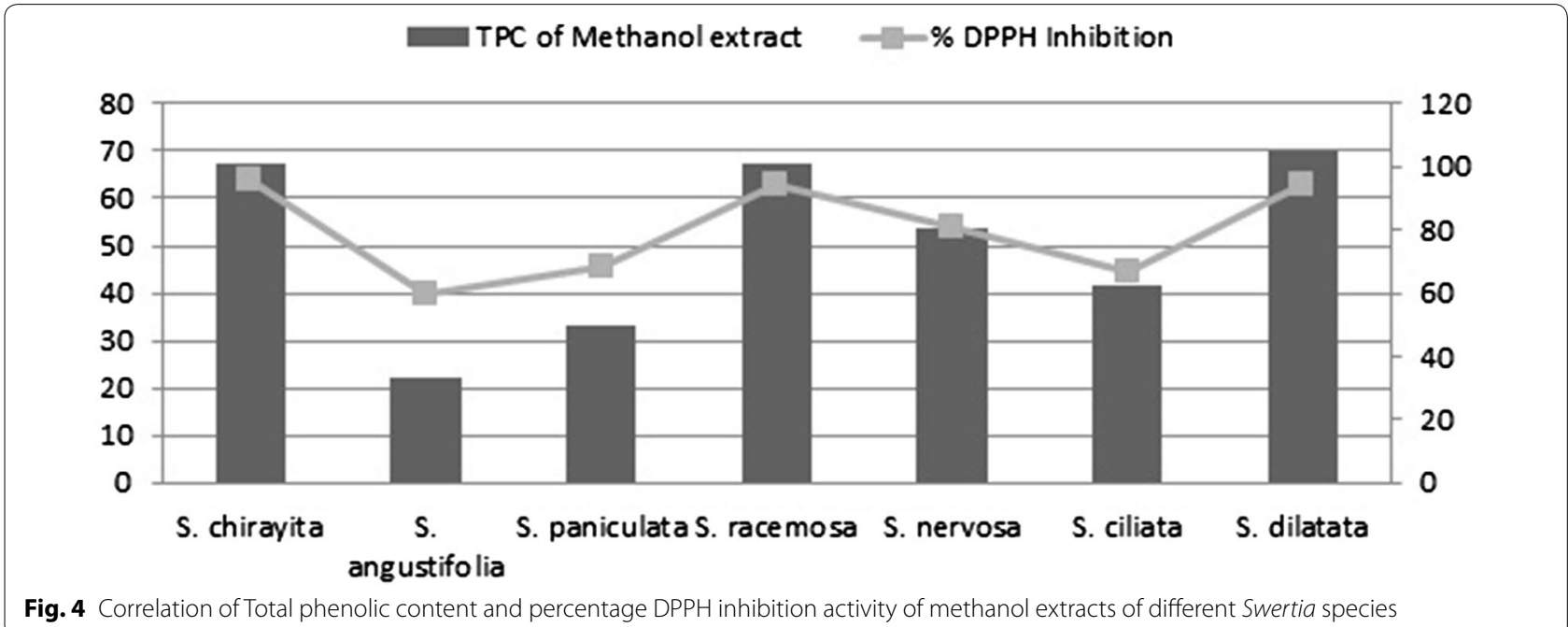

that have been associated with a wide range of biological and pharmacological properties [31,32].

The quantity of total phenolic content is directly related to the inhibition percentage of DPPH radicals. The higher the polyphenols, the greater is the radical scavenging capacity of the plant extracts. According to Fig. 4, a significant correlation of 0.977 between TPC and antioxidant activity for different methanol extracts was found as shown in Fig. 4. Phoboo et al. [10] has also reported a similar higher correlation between the two components.

\section{Identification of major phytochemicals by thin layer chromatography}

Standard graphs of Swertiamarin (Additional file 10) (Fig. 5), Amarogentin (Additional file 11) (Fig. 6) and
Mangiferin (Additional file 12) (Fig. 7) were obtained from marker compounds and these phytoconstituents were estimated from the crude methanol extracts using these calibration curves.

Swertiamarin was estimated higher in methanol extracts of SDI $(0.16 \pm 0.01 \mathrm{mg} / \mathrm{g})$ followed by SAN $(0.15 \pm 0.008 \mathrm{mg} / \mathrm{g}), \mathrm{SCH}(0.13 \pm 0.008 \mathrm{mg} / \mathrm{g})$, SPA $(0.08 \pm 0.001 \mathrm{mg} / \mathrm{g})$, SRA $(0.039 \pm 0.003 \mathrm{mg} / \mathrm{g})$, SNE $(0.04 \pm 0.002 \mathrm{mg} / \mathrm{g})$ and SCI $(0.01 \pm 0.002 \mathrm{mg} / \mathrm{g})$ dry weight of the samples (Additional files 13 and 14). Previous quantification studies done by Wang et al. [33] in various species of Swertia such as S. japonica, S. pseudochinesis and S. binchuangensis has reported comparable amount of swertiamarin from Chinese highlands. Similarly, Phoboo et al. [10], also quantified the aqueous and ethanol extracts of Swertia 


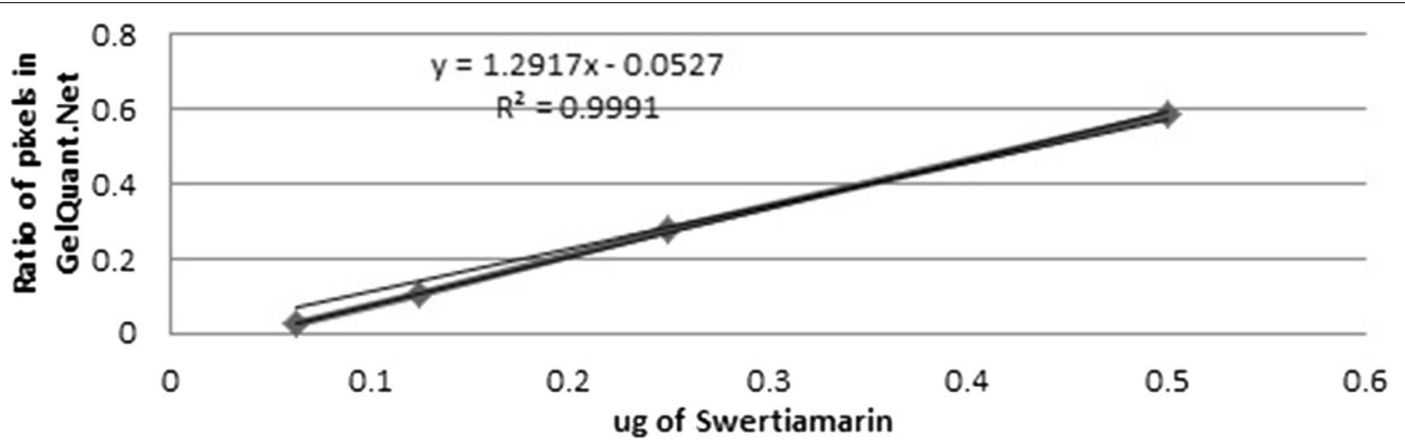

Fig. 5 Standard graph for Swertiamarin

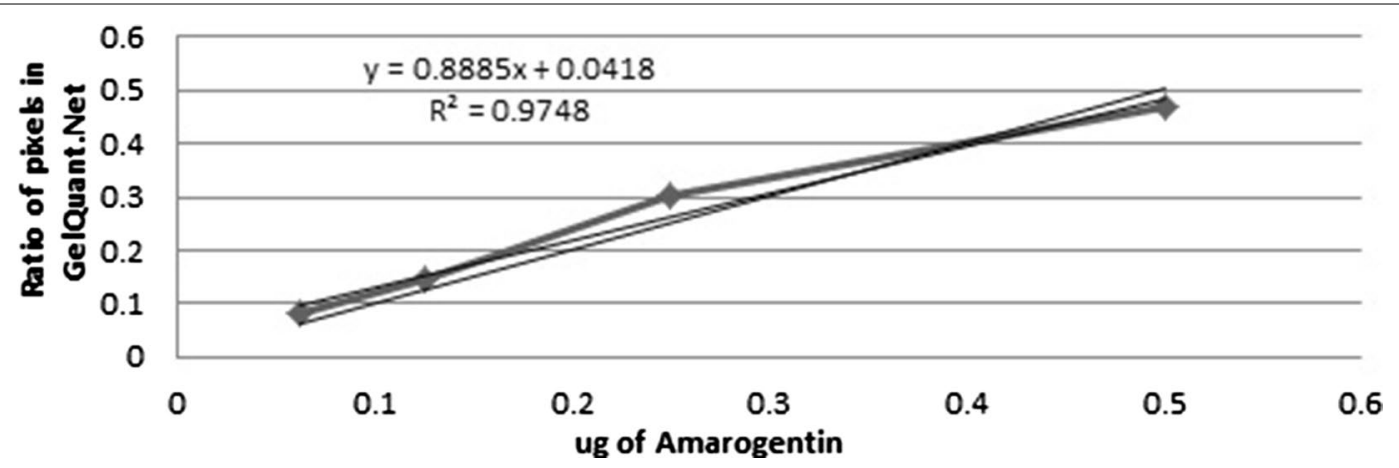

Fig. 6 Standard graph for Amarogentin

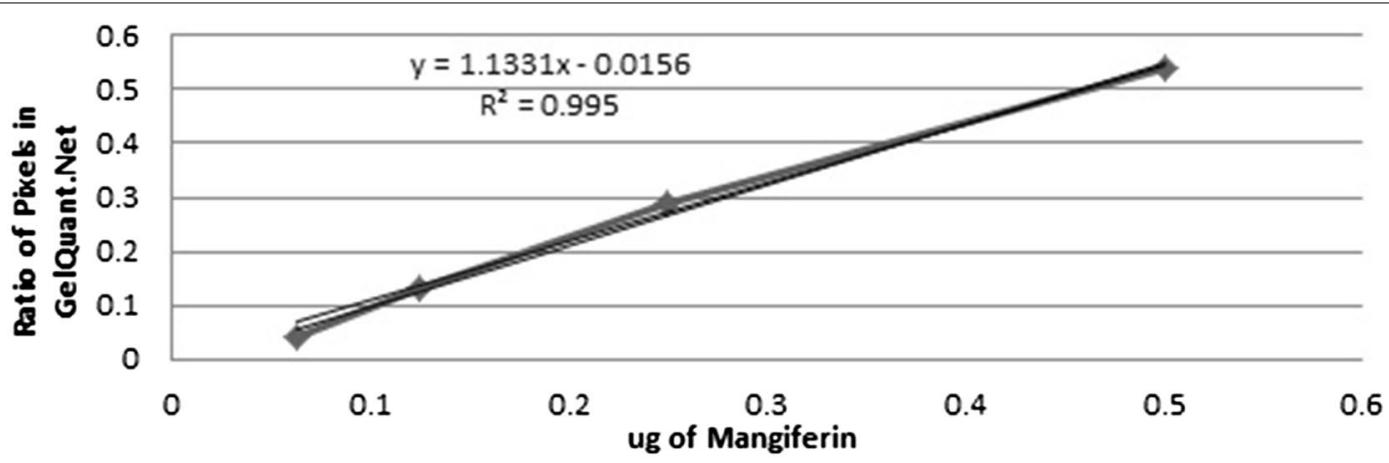

Fig. 7 Standard graph for Mangiferin

chirayita from Nepalese Himalayas. Swertiamarin is a secoirirdoid that has been reported to possess hepatoprotective, anti-inflammatory, anti-bacterial, anticholinergic and free radical scavenging. Its anti-lipidimic activity is comparable to the clinical drug Atorvastatin which may also contribute to its cardio-protective and anti-atherosclerotic role [34].

Estimation of Amarogentin showed variable results, higher values were seen in $\mathrm{SCH}(0.26 \pm 0.009 \mathrm{mg} / \mathrm{g})$ and SDI $(0.23 \pm 0.01 \mathrm{mg} / \mathrm{g})$ and comparatively lower values in SRA $(0.075 \pm 0.002 \mathrm{mg} / \mathrm{g})$, SPA $(0.048 \pm 0.002 \mathrm{mg} / \mathrm{g})$,
SNE $(0.028 \pm 0.003 \mathrm{mg} / \mathrm{g}), \mathrm{SCI}(0.027 \pm 0.005 \mathrm{mg} / \mathrm{g})$ and lowest in SAN $(0.012 \pm 0.0003 \mathrm{mg} / \mathrm{g})$ dry weight (Additional files 13 and 14). Phoboo et al. [10] and Wang et al. [33] have quantified amarogentin from Swertia chirayita, S. japonica, S. punicea and S. binchuangensis. Amarogentin is the bitterest compound known for its topoismerase inhibition [35], chemopreventive and anti-leishmanial properties [36]. Of the studies species of Swertia, the highest percentage of Amarogentin is found in S. chirayita, however the nearby species like $S$. bimaculata, $S$. 


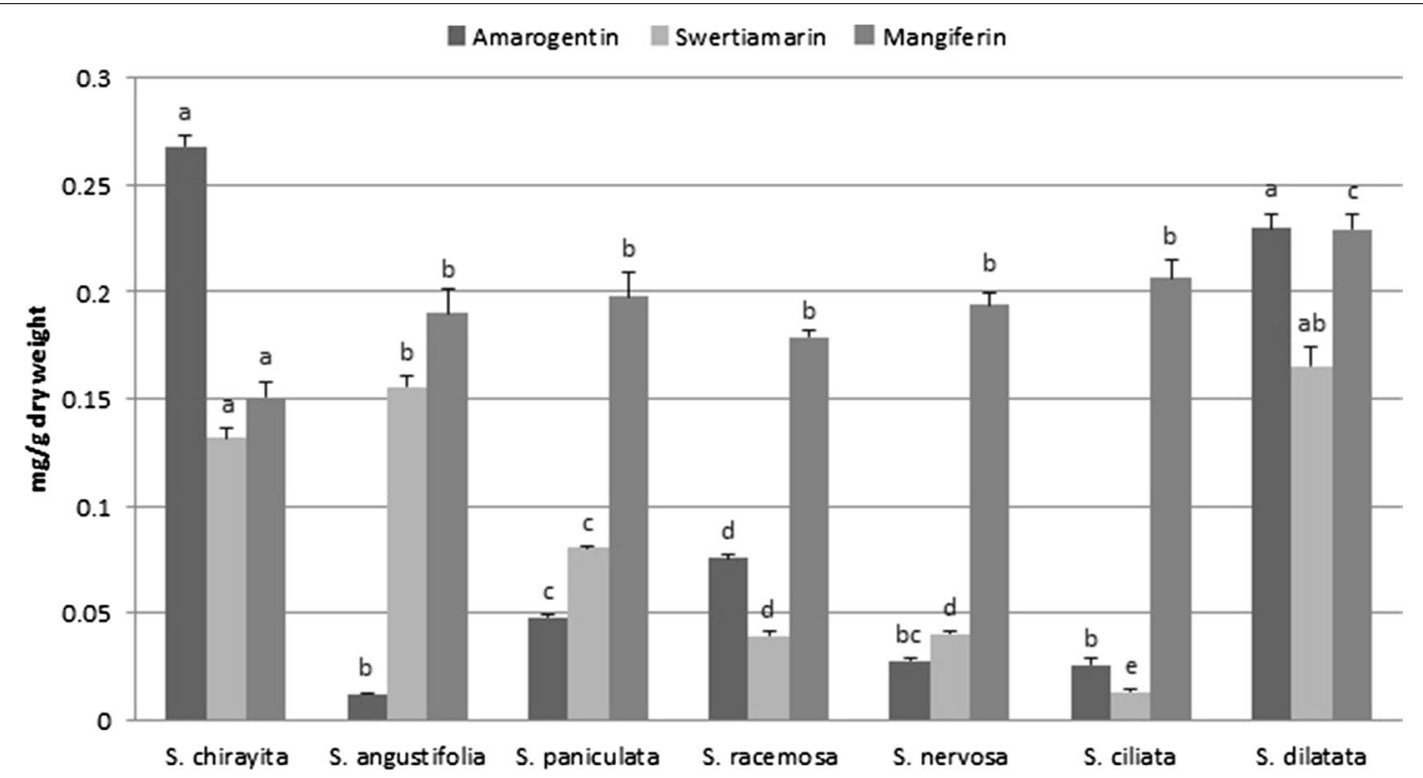

Fig. 8 Semi-quantitative estimation of Amarogentin, Swertiamarin and mangiferin in methanol extracts of different species of Swertia

dilatata and S. paniculata are known to have this bitter compound in lesser amount [12] (Fig. 8).

Likewise, Mangiferin estimation revealed a uniform quantity of mangiferin present in almost all of the samples (Additional files 15 and 16) in the order of SDI $(0.23 \pm 0.01 \mathrm{mg} / \mathrm{g})$, SCI $(0.206 \pm 0.01 \mathrm{mg} / \mathrm{g})$, SPA $(0.198 \pm 0.019 \mathrm{mg} / \mathrm{g})$, SNE $(0.194 \pm 0.01 \mathrm{mg} / \mathrm{g})$, SAN $(0.19 \pm 0.019 \mathrm{mg} / \mathrm{g})$, SRA $(0.178 \pm 0.005 \mathrm{mg} / \mathrm{g})$ and $\mathrm{SCH}$ $(0.15 \pm 0.01 \mathrm{mg} / \mathrm{g})$. Phoboo et al. [10] and Pandey et al. [37] reported the presence of mangiferin in S. chirayita, S. nervosa and S. ciliata. Mangiferin is a c-glucoxanthone that exhibits diverse pharmacological activities against arthritis, hepatitis, cardiac and mental disorders [38]. It is a good antioxidant agent with anti-tumor, antiviral, antiproliferative and diuretic properties (Pandey et al. [37]). Its anti-diabetic activity is similar to the clinical drug glibenclamide. Mangiferin significantly increased heart tissue phospholipids in isoproterenol induced cardio-toxic rats suggesting cardioprotective and hypolipidemic effects [39].

\section{Conclusion}

On the basis of this preliminary investigation, it can be concluded that the methanol extracts of other species of Swertia like S. paniculata, S. dilatata, S. racemosa, S. nervosa, S. ciliata and S. angustifolia also contains of large amount of phenolic and flavonoid compounds and exhibit high antioxidant activity. A significant correlation is found between the phenolic content and the antioxidant activities using in vitro DPPH radical scavenging assay. These species contain the bioactive compounds such as amarogentin, swertiamarin and mangiferin in appreciable amounts as shown by TLC. As the presence of secondary metabolites and major phytoconstituents are present in other species of Swertia in considerable amounts, these species should also be conceived for further studies to explore their potential and their isolation of bioactive compounds.

\section{Additional files}

Additional file 1: Swertia chirayita (Roxb. ex Fleming) $\mathrm{H}$. Karst.

Additional file 2: Swertia angustifolia Buch.-Ham. ex D. Don.

Additional file 3: Swertia racemosa (Griseb.) C.B. Clarke.

Additional file 4: Swertia nervosa (G. Don) C.B. Clarke.

Additional file 5: Swertia ciliata (D. Don ex G. Don) B.L. Burtt.

Additional file 6: Swertia dilatata C.B. Clarke.

Additional file 7: Phytochemical extraction.

Additional file 8: Quantification of flavonoids.

Additional file 9: Quantification of polyphenols.

Additional file 10: TLC profile of swertiamarin standard.

Additional file 11: TLC profile of amarogentin standard.

Additional file 12: TLC profile of manigiferin standard.

Additional file 13: TLC profile of amarogentin and swertiamarin for methanol extracts of different Swertia species. (From left: amarogentin and swertiamarin standard, SCH, SAN, SPA, SRA).

Additional file 14: TLC profile of amarogentin and swertiamarin for methanol extracts of different Swertia species. (From left: amarogentin and swertiamarin standard, SNE, SCI, SDI).

Additional file 15: TLC profile of maniferin for methanol extracts of different Swertia species. (From left: Mangiferin standard, SCH, SAN, SPA, SRA).

Additional file 16: TLC profile of mangiferin for methanol extracts of different Swertia species. (From left: Mangiferin standard, SNE, SCI, SDI). 


\section{Abbreviations}

TLC: thin layer chromatography; DPPH: 1,1-diphenyl-2 picryhydrazyl; NTFP. non timber forest product; GAE/g: galli acid equivalent per gram; QE/g: quercetin equivalent per gram; $\mathrm{IC}_{50}$ : inhibition concentration at $50 \%$; $\mathrm{SCH}$ : Swertia chirayita; SAN: Swertia angustifolia; SPA: Swertia paniculata; SRA: Swertia racemose; SNE: Swertia nervosa; SCI: Swertia ciliata; SDI: Swertia dilatata.

\section{Authors' contributions}

SK and NS carried out the laboratory work, acquired the data, performed statistical analysis and helped to draft the manuscript. DRP designed the experimental set up and helped in field visits; KT interpreted the raw data and assisted in its statistical analysis. All authors read and approved the final manuscript.

\section{Author details}

${ }^{1}$ Central Department of Biotechnology, Tribhuvan University, Kirtipur, Kathmandu, Nepal. ${ }^{2}$ Central Department of Botany, Tribhuvan University, Kirtipur, Kathmandu, Nepal.

\section{Acknowledgements}

This study was conducted in Central Department of Biotechnology, Tribhuvan University. The authors would like to thank the department and the lab members, who provided valuable feedback for the statistical analysis and draft preparation.

\section{Competing interests}

The authors declare that they have no competing interests.

Received: 18 April 2015 Accepted: 25 November 2015

Published online: 26 December 2015

\section{References}

1. Dewick PM. Tumor inhibition from plants. Tease and Evans; 1996.

2. Paterson I, Anderson EA. The renaissance of natural products as drug candidates. Science. 2005:310:451-3.

3. Cragg GM, Newman DJ, Snader KM. Natural products in drug discovery and development. J Nat Prod. 1997;60:52-60.

4. Joshi AR, Joshi DP. Endemic plants of Nepal himalaya: conservation status and future direction. Mt Env Develop. 1991;1:1-35.

5. Chaudhary RP. Biodiversity in Nepal: status and conservation. S. Devi, Saharanpur (India) and Tec Press Books, Bankok, 1998

6. Khanal S, Shakya N, Nepal N, Pant D. Swertia chirayita: the himalayan herb. Intl J Appl Sci Biotech. 2014;2:4.

7. Joshi K. Swertia L. (Gentianaceae) in Nepal: ethnobotany and agenda for sustainable management. Ethnobot Leafl. 2008;12:1-6.

8. Joshi AR, Joshi DP. Endemic plants of Nepal himalaya: conservation status and future direction. Mt Env Dev. 1991;1:1-35.

9. Barakoti TP, Chapagain T, Thapa Y, Bhusal C. Chiraito conservation and cultivation and cultivation workshop and achievement. Pakhribas, Dhankuta, Nepal: Nepal Agriculture Research Centre (NARC); 1999.

10. Phoboo S, Pinto MDS, Bhowmik PC, Jha PK, Shetty K. Quantification of major phytochemicals of Swertia chirayita, a medicinal plant from Nepal. Ecoprint. 2010;17:59-68.

11. Brahmachari G, Mondal S, Gangopadhyay A, Gorai D, Mukhopadhyay B, Saha S, Brahmachari AK. Swertia (Gentianaceae): chemical and pharmacological aspects. Chem Biodiv. 2004;1:1627-51.

12. Negi JS, Singh P, Rawat B. Chemical constituents and biological importance of Swertia: a review. Curr Res Chem. 2011;3:1-15.

13. Harborne JB. Phytochemicals methods. London: Chapman and Hall Ltd.; 1973. p. 49-188.

14. Trease GE, Evans WC. Pharmacognosy. 11th ed. London: Bailliere Tindall; 1989. p. 45-50.

15. Chang C, Yang M, Wen $\mathrm{H}$, Chern J. Estimation of total flavonoid content in propolis by two complementary colorimetric methods. J Food Drug Anal. $2002 ; 10: 178-82$
16. Chang LW, Yen WJ, Huang SC, Duh PD. Antioxidant activity of sesame coat. Food Chem. 2002:78:347-54

17. Blois MS. Antioxidant determinations by the use of a stable free radical. Nature. 1958;181:1199-200.

18. Wagner H, Bladt S, Zgainski EM. Plant drug analysis. Berlin: SpringerVerlag; 1983. p. 1-304

19. Biochemlabsolutions (2014) http://biochemlabsolutions.com/GelQuantNET.html. Accessed 21 Mar 2014

20. Baral D, Joshi SD, Manandhar MD. Studies on phytochemical screening of some Swertia species. Plant Resour Bull Dept Plant Resour 2012;34.

21. Middleton E Jr, Kandaswami C, Theoharides TC. The effects of plant flavonoids on mammalian cells: implications for inflammation, heart disease, and cancer. Pharmacol Rev. 2000:52:673-751.

22. Tripathi R, Mohan $H$, Kamat JP. Modulation of oxidative damage by natural products. J Food Chem. 2007;100:81-90. doi:10.1016/j. foodchem.2005.09.012

23. Havsteen $\mathrm{BH}$. The biochemistry and medical significance of the flavonoids. Pharmacol Ther. 2002;96:67-202.

24. Huang D, Ou B, Prior RL. The chemistry behind antioxidant capacity assays. J Agric Food Chem. 2005;53(6):1841-56.

25. Dembinska-Kiec A, Mykkänen O, Kiec-Wilk B, Mykkänen H. Antioxidant phytochemicals against type 2 diabetes. Br J Nutr. 2008;99:ES109-17.

26. Chen Y, Huang B, He J, Han L, Zhan Y, Wang Y. In vitro and in vivo antioxidant effects of the ethanolic extract of Swertia chirayita. J Ethnopharm. 2011;136:309-15

27. Dutta AK, Gope PS, Makhnoon S, Rahman S, Siddiquee MA, Kabir Y. Effect of solvent extraction on phenolic content, antioxidant and a-amylase inhibition activities of Swertia chiraiyta. Intl J Drug Dev Res. 2012:4:317-25.

28. Schwartz JL. The dual roles of nutrients as antioxidants and pro-oxidants: their effects on tumor cell growth. J Nutr. 1996:126S:1221-7.

29. Chan EWC, Lim YY, Omar M. Antioxidant and antibacterial activity of leaves of Etlingera species (Zingiberaceae) in peninsular Malaysia. Food Chem. 2007;104:1586-93.

30. Hajimehdipoor H, Dijoux-Franca MG, Mariotte AM, Amanzadeh Y, SadatEbrahimi SE, Ghazi-Khansari M, Mozaffarain V. Phytochemical study of Swertia longifolia. DARU. 2008;16:245-9.

31. Nagalekshmi R, Menon A, Chandrasekharan DK, Nair CKK. Hepatoprotective activity of Andrographis paniculata and Swertia chirayita. Food Chem Toxicol. 2011:49:3367-73.

32. Alam KD, Ali MS, Mahjabeen S, Parvin S, Akbar MA, Ahmed R. Analgesic activities of ethanol extract of leaf, stem and their different fractions of Swertia chirayita. Pakistan J Pharm Sci. 2010;23:455-7.

33. Wang D. Qualitative and quantitative analysis of Swertia herbs by high performance liquid chromatography diode array detector-mass spectrometry (HPLC-DAD-MS). Chem Pharm Bull. 2008:56:485-90.

34. Bhattacharya SK, Reddy PKSP, Ghosal S, Singh AK, Sharma PV. Chemical constituents of gentianaceae XIX: CNS-depressant effects of swertiamarin. J Pharm Sci. 1976;65:1547-9.

35. Ray S, Majumder HK, Chakravarty AK, Mukhopadhyay S. Amaraogentin, a naturally occurring secoiridoid glycoside and a newly recognized inhibitor of topoisomerase I from Leishmania donovani. J Nat Prod. 1996:59:27-9.

36. Medda S, Mukhopadhyay S, Basu MK. Evaluation of the in vivo activity and toxicity of amarogentin, an antileishmanial agent, in both liposomal and niosomal forms. J Antimicrob Chemother. 1999;44:791-4.

37. Pandey DK, Basu S, Jha TB. Screening of different east himalayan species and populations of Swertia L. based on exomorphology and mangiferin content. Asian Pac J Trop Biomed. 2012;2:S1450-6.

38. Jensen SR, Schripsema J. Chemotaxonomy and pharmacology of gentianaceae. In: Struwe L, Albert V (eds) Gentianaceae-systematics and natural history. Cambridge University Press. 2002, p. 573-631.

39. Andreu P, Colnot S, Godard C, Gad S, Chafey P, Niwa-Kawakita M, LaurentPuig P, Kahn A, Robine S, Perret C. Cryptrestricted proliferation and commitment to the Paneth cell lineage following Apc loss in the mouse intestine. Development. 2005;132:1443-5. 